\title{
Comparison of Shoulder Strength in Routinely Trained Badminton Players and Non-Badminton Players
}

\author{
Wong Zhen Feng, ${ }^{1}$ Hermawan Nagar Rasyid, ${ }^{2}$ Juliati $^{3}$ \\ ${ }^{1}$ Faculty of Medicine Universitas Padjadjaran, ${ }^{2}$ Department of Orthopedic and Traumatology \\ Faculty of Medicine Universitas Padjadjaran/Dr. Hasan Sadikin General Hospital Bandung, \\ ${ }^{3}$ Department of Anatomy, Cell Biology and Physiology Faculty of Medicine Universitas \\ Padjadjaran
}

\begin{abstract}
Background: : Shoulder pain is a common reason for patients to seek medical help in any healthcare center. Shoulder pain is influenced by a few factors such as gender, posture during daily activities, aging and psychological factors. Based on the study of Epidemiology of Injuries and Prevention Strategies in Competitive Swimmers, shoulder pain due to shoulder injuries can be reduced by strengthening the shoulder muscle. Badminton has become one of the most popular sports in Asia, especially in Indonesia. This study was conducted to determine if badminton is able to strengthen the shoulder muscle group.

Methods: A cross-sectional analytic experimental study was conducted on September 2015 at Lodaya Badminton Training Center and Bale Padjadjaran of Universitas Padjadjaran. Subjects were 30 healthy male routinely trained badminton players and 30 non-badminton players who voluntarily follow the rstudy procedures. Strength measurement procedures were provided to the subjects after getting informed consent. Data analysis was performed using T-test.

Results: The shoulder strength in routinely trained badminton players was significantly different from non-badminton players $(\mathrm{P}<0.05)$.

Conclusions: Shoulder strength can be improved through routine training of badminton to reduce risk of shoulder injury. ]

Keywords: Badminton players, shoulder pain, shoulder strength
\end{abstract}

\section{Introduction}

The shoulder joint is a joint with the most mobility in our body at the cost of its stability. ${ }^{1}$ The bony structure of the shoulder joint is often described as the golf ball and tee structure. ${ }^{2}$ The humeral is the golf ball and it is four times bigger than the tee, which is the glenoid, and hence, possesses a higher risk of injury. According to the study conducted by Schwarzkopf ${ }^{3}$ shoulder pain due to shoulder injuries has become a common complaint in healthcare centers.

Based on an article by Hermoso ${ }^{4}$ there are a few factors that can cause shoulder pain: aging which causes muscle degeneration, gender as females are usually more prone to shoulder pain, and daily work posture. Therefore, prevention of shoulder pain by strengthening the shoulder muscle is necessary for the population with high risk of shoulder pain.
Shoulder muscle strength training can improve shoulder health and reduce the risk of shoulder injury or shoulder pain. ${ }^{5}$ An article written by Labriola ${ }^{6}$ reported that stronger shoulder muscles helps in maintaining the shoulder stability as the rotator cuff muscle group can help maintaining the stability of the glenohumeral joint. However, due to the improvement of technology, the younger generation prefer a more sedentary lifestyle. Badminton is one of the most popular sports in Asia, especially in Indonesia. There are many reasons why badminton is popular, for example, it can improve physical and mental health, it has fairly low injury risks, it is easy to play, racquet used is very durable and most importantly, all ages can play this sport. Badminton is a sport that requires high functionality of the shoulder, especially the movement and strength of the shoulder. This study was aimed to discover if playing 
badminton can improve shoulder strength.

\section{Methods}

This study was a cross sectional analytic experimental study with paired observation and was conducted in September 2015 at Lodaya Badminton Training Center and Bale Padjadjaran of Universitas Padjadjaran. The sampling technique used in this study was consecutive random sampling and the calculation used the analytical study of paired continuous variables (one sided). By using Z-score of 1.96 and power of 1.00 , the minimal sample required for this study was 60 subjects. The data was collected from two groups of participants. The first group was routinely trained badminton players with at least two times of badminton training sessions in a week from Lodaya Badminton Training Center, while the second group was nonbadminton players from Bale Padjadjaran of UniversitasPadjadjaran. The study was conducted after obtaining ethical clearance from the Health Reserach Ethics Committee Faculty of Medicine Universitas Padjadjaran according to clearance letter number 3003/ UN6.C.C1/PP/2015.

This study was performed to determine the difference of shoulder strength between routinely trained badminton players and nonbadminton players. Furthermore, shoulder strength measurement procedure was explained to the subjects after getting inform consent agreement from the participants. The subjects were male because shoulder strength can differ in gender based on the study conducted by Katolik. ${ }^{7}$ The subject's age was ranged from 18-59 because the normal constant score were not significantly different among these age groups. ${ }^{7}$ The researcher also wanted to determine whether badminton exercises can decrease the speed of shoulder muscle strength degeneration in older people. Then, subjects were chosen according to the inclusion and exclusion criteria. This study was a preliminary study; hence some criteria and methods in data collection were decided by the author based on his own experience in badminton.

The inclusion criteria for this study were male badminton players of age range 18-59 years, routinely trained, and male individual with less than two times of badminton training sessions in a week. Subjects from both groups should not be affected by current or previous shoulder injuries, and no current use of medication which $t$ could influence the muscles strength. The exclusion criteria were female, physically and mentally dysfunction, had an upper limb injury such as CarpalTunnel or Tennis Elbow Injury, subjects were actively involved in overhead exercise such as baseball, tennis and handball and occupations that required heavy lifting. The apparatus used in the shoulder measurement was the Baseline pull and push dynamometer, which can measure the muscle strength in kilograms or pounds. It has 2 ends, one side is push and one side is pull. ${ }^{8}$ To measure shoulder strength, subjects were asked to raise their dominant hand to 90 degree and the examiner used the baseline push and pull dynamometer to give pressure on the shoulder. Subjects were asked to resist the force. The resistant of each subject was recorded based on the dynamometer reading as pounds.

The sample size of this study was 30 routinely trained badminton players and 30 non-badminton players who voluntarily followed the study procedures. All the subjects met the inclusive and exclusive criteria before the selection. The Mann-Whitney test was conducted to check whether the age in these groups were normally distributed. Next, independent T-test was performed to calculate the mean and standard deviation of shoulder strength between these groups. Lastly, the Regression Test was conducted to determine whether there was a difference in shoulder strength between routinely trained badminton players and non-badminton players using the Statistical Package for Social Sciences. Statistically significant result was considered when $\mathrm{p}<0.05$.

\section{Results}

There were 30 male routinely trained badminton players and 30 non-badminton players included in the study to determine whether there was a different of shoulder strength between these two groups.

The P-value found using the Mann-Whitney Test showed the age was not normally distributed. Hence, age difference between these groups need to be controlled using Regression Test (Table 1).

The mean shoulder strength of routinely trained badminton players was higher than the mean shoulder strength of non-badminton players. The P-value for the difference of shoulder strength between routinely trained badminton players and non-badminton players was $<5 \%$, so the null hypothesis was rejected. However, the researcher found that 
Table 1 Total Number and Median (Interquatile Range) of Age of Routinely Trained Badminton Players and Non-Badminton Players

\begin{tabular}{lccc}
\hline \multicolumn{1}{c}{ Group } & $\begin{array}{c}\text { Routinely Trained } \\
\text { Badminton Players }\end{array}$ & $\begin{array}{c}\text { Non-Badminton } \\
\text { Players }\end{array}$ & P-value* $^{*}$ \\
\hline $\begin{array}{l}\text { Number of Subjects } \\
\text { Median (IQR)** }\end{array}$ & $\mathrm{N}=30$ & $\mathrm{~N}=30$ & \\
Age & $45(13)$ & $18(2)$ & $<0.001$ \\
\hline
\end{tabular}

Note: *P value is found using Mann-Whitney Test, ${ }^{* *} \mathrm{IQR}$ is Interquatile Range

Table 2 Comparison of Shoulder Strength in Mean \pm Standard Deviation on Routinely Trained Badminton Players and Non-Badminton Players

\begin{tabular}{lccc}
\hline & $\begin{array}{c}\text { Routinely Trained } \\
\text { Badminton Players }\end{array}$ & $\begin{array}{c}\text { Non-Badminton } \\
\text { Players }\end{array}$ & P-value* $^{*}$ \\
\hline Mean $\Delta \pm \mathrm{SD}^{* *}$ & $56.65 \pm 6.78$ & $44.29 \pm 4.82$ & 0.011
\end{tabular}

Note: *P value is found using Independent T-test, ${ }^{* *}$ SD is Standard Deviation

it was necessary to control the age since the age variance between these groups was large. Hence, linear multiple regression test was performed to control the age difference between these groups (Table 2).

Moreover, after controlling the age difference using multiple linear regression test, the strength difference between these groups was $11.45 \mathrm{lbs}$ and the P-value for the difference of shoulder strength between the routinely trained badminton players and non-badminton players was $<5 \%$, so null hypothesis was rejected (Table 3 ).

After controlling the age difference using the multiple linear regression test, the strength difference between these groups was 11.45lbs and the $p$ value for the difference of shoulder strength between the routinely trained badminton players and non-badminton players was $<5 \%$, so null hypothesis was rejected.

\section{Discussion}

Shoulder pain is the third most common reason for the patient to seek for medical musculoskeletal consultation. ${ }^{9}$ Shoulder pain can affect the ability of an individual to carry out daily activities. The quality of life will be significantly affected if an individual is unable to perform normal daily activities. Thus, an individual is encouraged to carry out some prevention program such as shoulder strengthening exercises to increase their shoulder health.

According to the study of Ronai ${ }^{10}$ if a patient undergoes some conditioning programs that focus on the restoration of shoulder strength and flexibility of shoulder structure, it can enhance the shoulder function and health. The strengthening of core muscles

Table 3 Comparison of Shoulder Strength between Routinely Trained Badminton Players and Non-Badminton Players

\begin{tabular}{|c|c|c|c|c|c|c|}
\hline \multirow[t]{2}{*}{ Model } & \multicolumn{2}{|c|}{$\begin{array}{l}\text { Unstandardized } \\
\text { coefficients }\end{array}$} & \multirow[t]{2}{*}{$\mathbf{t}$} & \multirow[t]{2}{*}{ P-value* } & \multicolumn{2}{|c|}{$95 \%$ confidence interval for $B$} \\
\hline & B & Std.Error** & & & Lower Bound & Upper Bound \\
\hline (Constant) & 43.59 & & & & & \\
\hline Shoulder** Strength & 11.45 & & & & & \\
\hline Age & 0.04 & & & & & \\
\hline
\end{tabular}

Note: *P value is found using Linear Multiple Regression Test, **Std.Error is Standard Error, ***Shoulder Strength use Pounds as unit 
is an essential component in any injury prevention program. ${ }^{11}$ Therefore, the shoulder strengthening exercise is an important factor for the subject to maintain healthy shoulders and reduce the risk of shoulder injuries. For example, the overhead barbell press exercises can be used to enhance shoulder function and stability. ${ }^{12}$ Badminton is one of the commonly played sports in the community and it uses a lot of overhead movements of the upper limb. It is considered as an endurance training to improve the cardiovascular system health. A study performed by Silvennoinen ${ }^{13}$ stated that endurance exercises can increase the muscular strength by promoting the release of PGC-1 alpha. PGC-1 alpha is used as a marker for mitochondria biogenesis after exercise. Therefore, badminton is suitable for an individual to improve shoulder strength.

The results showed that there were significant differences between the routinely trained badminton players and nonbadminton players. The null hypothesis of routinely trained badminton players had the same shoulder strength with non-badminton players was rejected as the $p$ value $<0.05$.

Furthermore, the median age of the routinely trained badminton players was significantly higher than the non-badminton players. Based on this, the examiner found that although the median age of the routinely trained badminton players was older than of the non-badminton players, the result of strength measurement was still higher in the routinely trained badminton players (Table 1). Thus, badminton exercises can strengthen shoulder muscles inspite of aging, where muscle function is greatly decreased. ${ }^{14}$ The non-badminton players median age was 18 years old and yet their shoulder strength was lower than the active routinely trained badminton players, hence possessing a higher risk of injury since their shoulder strength was lower than the routinely trained badminton players.

Additionally, the mean shoulder strength of routinely trained badminton players was higher than the shoulder strength of nonbadminton players. However, even though the results was significant when $\mathrm{p}<0.05$, however, the researcher refused to analyze the data in the table since the age was not yet a control factor (Table 2).

Moreover, this study found that badminton exercises were able to strengthen the shoulder muscle and therefore, could maintain healthy shoulders. Based on a research by Labriola ${ }^{6}$ it showed that shoulder muscle strength can help to maintain the stability of shoulder joint especially the rotator cuff muscle group, which is an effective compressor of glenohumeral joint. Thus, the results showed clearly that routinely trained badminton group had a healthier shoulder muscle group.

There are two limitations in the study. Firstly, this study only measured the dominant hand of the subjects as it was commonly used in routinely trained badminton players. However, it was tried to exclude all possible confounding factors such as heavy lifting, hence ensuring that increase in muscle strength was only due to badminton training. Secondly, the study only tested male subjects. Further studies should be conducted to test whether other overhead exercises such as tennis and baseball can strengthen the shoulder muscle.

In conclusion, even though badminton can improve shoulder strength; over-practicing the sports can cause injuries, such as microtrauma stress instead. ${ }^{15}$ Hence, with proper amount and duration of badminton training, a person's shoulder strength can be improved and risk of shoulder injury can be reduced. Thus, with these positive results, we can suggest the community to join badminton activities since it can help maintain shoulder health and reduce the risk of shoulder injury.

\section{References}

1. Wilk KE, Macrina LC, Reinold MM. Nonoperative rehabilitation for traumatic and atraumatic glenohumeral instability. N Am J Sports Phys Ther. 2006;1(1):16-31.

2. Dumont GD, Russell RD, Robertson WJ. Anterior shoulder instability: a review of pathoanatomy, diagnosis and treatment. Curr Rev Musculoskelet Med. 2011;4(4):200-7.

3. Schwarzkopf R, Oron A, Loebenberg M. [Shoulder pain: assessment, diagnosis and treatment of common problems]. Harefuah. 2008;147(1):71-6, 93.

4. Hermoso FE, Calvo E. Shoulder pain in the elderly. Aging Health. 2009;5(5):711-8.

5. Niederbracht $Y$, Shim AL, Sloniger MA, Paternostro-Bayles M, Short TH. Effects of a shoulder injury prevention strength training program on eccentric external rotator muscle strength and glenohumeral joint imbalance in female overhead activity athletes. J Strength Cond Res. 2008;22(1):140-5.

6. Labriola JE, Lee TQ Debski RE, McMahon PJ. Stability and instability of the glenohumeral joint: The role of 
shoulder muscles. J Shoulder Elbow Surg. 2005;14(1):S32-8.

7. Katolik LI, Romeo AA, Cole BJ, Verma NN, Hayden JK, Bach BR. Normalization of the constant score. J Shoulder Elbow Surg. 2005;14(3):279-85.

8. Maayah MF, Al-Jarrah MD, El Zahrani SS, Alzahrani AH, Ahmedv ET, Abdel-Aziem AA, et al. Test-retest strength reliability of the Electronic Push/Pull Dynamometer (EPPD) in the measurement of the quadriceps and hamstring muscles on a new chair. Open Journal of Internal Medicine. 2012;2(2):123-8.

9. Mitchell C, Adebajo A, Hay E, Carr A. Shoulder pain: diagnosis and management in primary care. BMJ. 2005;331(7525):1124-8.

10. Ronai P. Exercise modifications and strategies to enhance shoulder function. Strength and Conditioning Journal. 2005;27(4):36-45.

11. Wanivenhaus F, Fox AJS, Chaudhury S, Rodeo SA. Epidemiology of injuries and prevention strategies in competitive swimmers. Sports Health. 2012;4(3):24651.

12. McKean MR, Burkett BJ. Overhead shoulder press - In-front of the head or behind the head?. Journal of Sport and Health Science. 2015;4(3):250-7.

13. Silvennoinen M, Ahtiainen JP, Hulmi JJ, Pekkala S, Taipale RS, Nindl BC, et al. PGC-1 isoforms and their target genes are expressed differently in human skeletal muscle following resistance and endurance exercise. Physiological Reports. 2015;3(10):e12563.

14. Eibich P, Buchmann N, Kroh M, Wagner GG, Steinhagen-Thiessen E, Demuth I, et al. Exercise at different ages and appendicular lean mass and strength in later life: results from the berlin aging study II. J Gerontol A Biol Sci Med Sc. 2015;00(00):6.

15. Reinold MM, Curtis AS. Microinstability of the shoulder in the overhead athlete. Int J Sports Phys Ther. 2013;8(5):601-16. 